\title{
As relações entre o Estado e a população pobre e negra no Brasil: necropolítica tropical
}

The relations between the State and the poor and black population in Brazil: tropical necropolitics

\author{
Waldenilson Teixeira Ramos \\ Debora Inêz Brandão \\ Mauro Andrade Silva \\ Danichi Hausen Mizoguchi \\ Universidade Federal Fluminense
}

\section{Resumo}

0 presente artigo aborda algumas diretrizes e práticas da necropolítica tropical e do racismo que opera nas relações entre o Estado e a população pobre e negra no Brasil. Notadamente, este trabalho interessa-se pela política mortífera executada pelas polícias, que não hesitam em matar pessoas que habitam territórios periféricos dos grandes centros urbanos do país. Sabe-se que essa relação não é nova. Ao contrário, advém dos tempos da escravidão institucional e permanece mesmo depois de 133 anos da abolição. Intentamos aqui, amparados principalmente nos trabalhos de Michel Foucault e Achille Mbembe, forjar pistas para uma espécie de ascese negra como enfrentamento à dimensão necropolítica e racista do capitalismo contemporâneo. A construção do artigo se dá na costura entre conceitos, notícias cotidianas e produções artísticas que investigam e evidenciam a manutenção do racismo de estado, mas também nas práticas de resistência forjadas no presente.

Palavras-chave: Racismo; Estado; Necropolítica; Ascese

\begin{abstract}
This article discusses some guidelines and practices of tropical necropolitics and racism that operates in relations between the State and the poor and black population in Brazil. Notably, this work is interested in the deadly policy carried out by the police, who do not hesitate to kill people who inhabit the peripheral territories. It is known that this relationship is not new. On the contrary, it comes from the institutional slavery and remains even after 133 years of abolition. We intend here, supported mainly by the works of Michel Foucault and Achille Mbembe, to forge clues to a kind of black asceticism as a confrontation with the necropolitical and racist dimension of contemporary capitalism. The construction of the article takes place in the seam between concepts, daily news and artistic productions that investigate and show the maintenance of state racism, but also in the resistance practices forged in the present.
\end{abstract}

Keywords: Racism; State; Necropolitics; Ascese 


\section{INTRODUÇÃO: NOSSAS NOITES DO NORTE}

A escravidão permanecerá por muito tempo como a característica nacional do Brasil. (...). Ela é o suspiro indefinível que exalam ao luar as nossas noites do norte.

(Joaquim Nabuco, 1976, p. 120)

Em um mundo e em um país circundado por suspiros advindos dos efeitos e heranças do jugo brutal da escravidão, parece que tudo que nos resta é inalar o odor do sangue que escorre pelas ruas e transpirar a desesperança. Todavia, desejantes de fazer da respiração o fôlego que reafirma a vida e a manifestação das diferenças, forjamos este trabalho sob sopros animadores e forças criadoras. Para tanto, porém, é necessário antes realizar o recorte e a exposição do que se apresenta como força política brutal e impiedosa endereçada aos corpos negros.

Efetuamos a aposta teórica-metodológica deste trabalho alicerçados no compromisso político de transformação do mundo - que, evidentemente, nos parece ser uma das tarefas contemporâneas da Psicologia. Nossos olhos e ouvidos se mantiveram atentos aos noticiários que apresentam a particularidade da experiência negra no Brasil - uma espécie de ontologia racial comum. Por outro lado, a genealogia que nos forneceu a tecedura social que aqui se fez presente marca também toda força inventiva e molecular que culminou e ainda se presentifica em protestos e revoltas dos que não aceitam o legado escravocrata e genocida em seus corpos.

Fizemos de nossa coleta empírica ação mobilizadora: histórias de vidas, nomes de crianças e famílias, poesia e músicas que levaram multidões a reivindicar 0 direito a uma vida digna e sem medo. São esses os elementos primordiais de nossa empiria: vitalizamo-nos com os recortes do real que dão norte às nossas noites do norte - para usar a expressão do abolicionista Joaquim Nabuco (1976) em seu livro de memórias, Minha formação.

O movimento é quase o mesmo. Sem muita criatividade e sem muita esperteza, mas com muita eficácia: as máquinas de pólvora cada vez maiores e cada vez mais silenciosas. Geralmente fica-se sabendo que a polícia irá invadir quando rodeiam demais a favela. Pode haver helicópteros também. Às vezes acontece alguma negociação entre a polícia colonial da família real portuguesa e os dissidentes brasileiros - pretos e pardos traidores da nação, que romperam com o projeto civilizatório de um Brasil branco, de família burguesa, mulheres frígidas e homens sempre muito potentes com suas pastas de documentos cuidando do algoritmo da riqueza que não sabemos onde pode estar. Repetindo o gesto 
estruturante de formação da polícia militar no Brasil ${ }^{1}$, as políticas públicas de segurança no país têm como diretriz básica a proteção à propriedade privada e 0 ataque aos pretos e pobres.

O cantor e compositor baiano Caetano Veloso - ex-prisioneiro da ditadura civilempresarial-militar brasileira na década de 1960 e um dos personagens principais do movimento tropicalista - disse muito bem no refrão da música Haiti, composta com Gilberto Gil após ambos testemunharem do alto do adro da Fundação Casa de Jorge Amado o modo como a polícia tratava os meninos pobres no Pelourinho da cidade de Salvador: "O Haiti é aqui, o Haiti não é aqui" (Veloso, 2012). Esse paradoxo shakespeariano - ser e não ser aqui - se justifica pelo fato de que o Haiti foi palco da primeira revolução negra nas Américas e é hoje o país mais pobre do continente. 0 Brasil também é um país paupérrimo, porém nunca fez a revolução que lá se viu - e é também por isso que, a despeito da abolição, como disse Joaquim Nabuco (1976), a escravidão permanece e permanecerá por muito tempo como característica nacional.

O Brasil foi o país que mais importou mulheres, homens e crianças em condição de escravizados entre o século XVI e meados do XIX. Porém, a letra da canção de Caetano e Gil demarca uma diferença central entre a quantidade e a qualidade do país em seu grau de projeto e aquilo que ele realmente é:

Quando você for convidado

Pra subir no adro da Fundação Casa de Jorge Amado

Pra ver do alto a fila de soldados, quase todos pretos

Dando porrada na nuca de malandros pretos

De ladrões mulatos

E outros quase brancos

Tratados como pretos

Só pra mostrar aos outros quase pretos

E são quase todos pretos

Como é que pretos, pobres e mulatos

E quase brancos, quase pretos de tão pobres são tratados.

(Veloso, 2012).

No Brasil, maior país da América do Sul, a relação entre brancos e pretos pouco efetiva conquistas do âmbito dos direitos civis. O problema é de direito penal: $80 \%$ dos brasileiros são pretos e pardos, e vivenciam o diagrama necropolítico (Mbembe, 2018) tropical conduzido pelos quase brancos - cristãos, novos ricos, empresários, governantes do Estado - cristianizados e europeizados. A paixão pela morte dá-se também na repetição micropolítica de quem encontra a sua

${ }^{1}$ No dia 13 de maio de 1809 o Príncipe Regente Dom João assinou um decreto institucionalizando pela primeira vez no Brasil a Divisão Militar da Guarda Real de Polícia da Corte Portuguesa. 
colônia para salvar os selvagens domesticando-os e/ou aniquilando-os. A psicóloga e artista Grada Kilomba chamou de outridade a promessa de um quase que o qual catalisa a operação racista, colonial, machista e violenta da estrutura ainda escravocrata. 0 processo, então, é óbvio na medida em que se sabe o que o faz pulsar: a morte do outro que outrora chamaram de animais e hoje chamam de negro.

\section{A PENUMBRA DA MORTE}

No começo de 2020, o coronavírus começava a circular mundialmente. Todavia, o valor não qualificado da morte - que supostamente se colocava diante de um vírus que, diferentemente do Estado, não escolhe seus alvos a partir de crivos de raça, classe ou gênero - não foi capaz de suspender o modo como os povos originários, os pobres, os pretos, os mulatos, os sem moradia, os sem acesso à educação e os sem emprego estão acostumados a viver. Mesmo sob a pandemia, os morros continuaram a ser invadidos por agentes do Estado. Em agosto deste mesmo ano, o Instituto de Pesquisa Econômica Aplicada (IPEA) publicou o Atlas da Violência 2020, divulgando o resultado das pesquisas realizadas entre 2008 a 2018. As estatísticas apresentam aquilo que aparece como uma evidência para quem habita qualquer grande centro urbano brasileiro: $91,8 \%$ das vítimas de homicídios são homens entre 15 e 29 anos - com maior incidência de morte no pico da juventude, aos 21 anos. Os homens pardos e negros são 74\%; 46,6\% dos homens negros, vítimas, têm entre 3 e 7 anos de escolaridade; e $77,1 \%$ são mortos por armas de fogo. O local mais comum dessas mortes é a rua - com 69,4\% de ocorrências para homens negros. É óbvio que estamos diante do diagrama de poder soberano (Foucault, 1979) que Achille Mbembe (2018) atualiza para o presente: fazer morrer e deixar viver.

Ordenada pelas máquinas capitalistas neoliberais e fascistas que nos governam, as vidas negras brasileiras têm sido forjadas ininterruptamente sob a penumbra da morte. Estatisticamente, os feitos para morrer são os homens negros com baixo acesso às escolas, submetidos a prisões compulsórias, à inserção precoce no tráfico de drogas, ao sofrimento dos efeitos do uso abusivo de drogas. É majoritariamente sobre eles que opera o genocídio cotidiano realizado pelo braço armado do Estado. Por sua vez, as mulheres negras que sobrevivem a essa forma mais direta de extermínio têm suas vidas marcadas pela submissão: são provedoras do lar, mães solteiras que vivem em condições precárias de moradia e em constante situação de violência doméstica e de estupro.

0 fato é que, ainda que no ano passado o país se encontrasse sob a maior crise sanitária de sua história, o cenário calamitoso não representou nada para uma força policial sedenta por sangue - força policial esta que, segundo relatório 
da Rede de Observatórios de Segurança publicado em dezembro de 2020, em apenas seis meses, causou um número de mortes nunca alcançado nas últimas duas décadas. Quantos mais teriam sido mortos por aqueles que prometeram proteger a vida? Quantas crianças inocentes precisam ter seus sonhos interrompidos brutalmente para se evidenciar a guerra estabelecida a um determinado território?

\section{PROMESSAS E DIFERENÇAS DE TRATAMENTO}

Ao se observar o cenário de sangue que se estende sobre as políticas de segurança pública no Brasil, pode-se acreditar que o mundo é este mesmo e que não há nada a se fazer. Sabe-se que

[A] política que rege os processos de subjetivação próprios do capitalismo financeiro que se instalou no planeta a partir do final dos anos 1970 aparece recentemente em nosso país em uma estranha conjunção entre o discurso fascista e as diretrizes econômicas neoliberais. Concomitante a essa conjugação, emergiu um incremento do questionamento acerca da eficácia das políticas de segurança pública que estão sendo empregadas para o controle da violência urbana, notadamente nas capitais estaduais. (Gimenes e Mizoguchi, 2019, p. 2)

Essa conjuntura efetua sobre o campo social um sentimento de medo, desesperança e falta de legitimidade em relação às políticas públicas efetivadas pelo Estado Democrático de Direito em que supostamente vivemos no Brasil - e mais especificamente em relação a determinadas garantias que estão sob a responsabilidade da gestão das polícias. A polícia militar é integrante estratégica do Sistema Único de Segurança Pública (SUSP). Segundo a Lei $n^{\circ} 13.675$, de 11 de junho de 2018, o SUSP foi criado "com a finalidade de preservação da ordem pública e da incolumidade das pessoas e do patrimônio". (Lei n $\mathrm{n}^{\circ} 13.675$, de 11 de junho de 2018). Como forma de dar notoriedade ao seu compromisso com a segurança da vida e a garantia da harmonia social, polícias em todo o país realizam juramento que reitera este compromisso. No Estado do Rio de Janeiro, não é diferente:

Ao ingressar na Polícia Militar do Estado do Rio de Janeiro, perante a Bandeira do Brasil e pela minha honra, prometo regular minha conduta pelos preceitos da moral e da legalidade, cumprir rigorosamente as ordens legais das autoridades a que estiver subordinado e dedicar-me inteiramente ao serviço da Pátria, ao serviço da Polícia Militar, à proteção da vida, à manutenção da ordem pública e à segurança da comunidade, mesmo com o sacrifício da própria vida. (Assembleia Legislativa do Estado do Rio de Janeiro [Alerj], Projeto de Lei n 556, de 10 de junho de 1999, artigo 1) 
Neste cenário juramental, indicam-se as funções da polícia: dedicação integral à pátria, à proteção da vida e à segurança da comunidade (Projeto de Lei $\mathrm{n}^{\circ}$ 556, de 10 de junho de 1999). Sobre essa mesma ótica constitucional, talvez pudesse se dizer que não há o que temer e que a vida será assegurada. Todavia, o sentimento que se espalha sobre determinados territórios é o de perda, dor e revolta - o que é compreendido facilmente quando se evidencia a brutalidade necropolítica assumida pelo Estado no encontro com os corpos ditos marginalizados. Diante da promessa de garantia fundamental à vida e da brutalidade cotidiana que se endereça à população negra e pobre no Brasil, emerge um dos maiores e centrais questionamentos atuais: segurança e garantia de direitos civis e constitucionais para quem? A quem este dispositivo de coesão serve? Em quais territórios as forças se apresentam como os garantidores da harmonia e conservadores da vida e onde essas mesmas forças se apresentam como aniquiladores da vida e promotores da brutalidade?

Infelizmente, encontramos as respostas para tais questões debruçando-nos sobre a realidade e ouvindo pessoas como o tenente-coronel Ricardo Augusto do Nascimento de Mello Araújo, das Rondas Ostensivas Tobias de Aguiar (ROTA), o qual, em uma entrevista ao UOL, deu o seguinte depoimento quando foi interrogado acerca das diferenças de abordagem policial nos diversos territórios da cidade:

É uma outra realidade. São pessoas diferentes que transitam por lá. A forma dele abordar tem que ser diferente. Se ele [policial] for abordar uma pessoa [na periferia], da mesma forma que ele for abordar uma pessoa aqui nos Jardins [região nobre de São Paulo], ele vai ter dificuldade. Ele não vai ser respeitado (Adorno, 2017, § $1^{\circ}$ ).

\section{(...)}

Da mesma forma, se eu coloco um [policial] da periferia para lidar, falar com a mesma forma, com a mesma linguagem que uma pessoa da periferia fala aqui no Jardins, ele pode estar sendo grosseiro com uma pessoa do Jardins que está ali, andando. 0 policial tem que se adaptar àquele meio que ele está naquele momento. (Adorno, 2017, § $2^{\circ}$ )

A fala do tenente-coronel escancara as diferenças evidentes no trato das políticas de segurança pública no Brasil. O privilégio fica evidente quando se trata de um território considerado nobre, como o bairro dos Jardins, em São Paulo, região predominantemente ocupada por pessoas com maior poder aquisitivo e de pele branca, onde a força policial terá uma performance protetiva e cautelar. Já quando se trata de um território considerado mais periférico, como, por exemplo, boa parte das favelas de São Paulo, do Rio de Janeiro e de outras grandes cidades brasileiras em que majoritariamente vivem pessoas negras, os 
policiais assumem abordagens agressivas e sanguinárias. 0 que é nodal no problema da falta de isonomia das políticas de segurança pública brasileiras é a constatação de práticas racistas em diversas instituições ditas democráticas e é com elas que nossa necropolítica histórica e cotidiana se atualiza e se fortalece ininterruptamente.

\section{HISTÓRIAS E VIDAS}

Ágatha Vitória Sales Félix, filha única de uma família que se esforçava diariamente para proporcionar as condições mínimas para que pudesse realizar seus sonhos. A menina queria em ser bailarina, estudava balé e cursava inglês. Por volta das vinte e uma horas de uma sexta-feira, Ágatha retornava para casa junto com sua mãe após mais uma longa jornada de esforços e estudos. Parecia ser apenas mais um dia que chegava ao fim e a aproximava de seus desejos futuros. Abruptamente, a noite marcou o fim dos sonhos e esforços da pequena garota e de sua família. A vida de Ágatha terminou apenas oito anos após ter começado. Ágatha e sua família moravam no Complexo do Alemão - zona norte da cidade do Rio de Janeiro. Lá, como em quase todas as favelas da capital fluminense, as intervenções violentas e brutais das forças policiais são o grande fantasma que assola os moradores. As fardas da defesa se apresentam com as balas perdidas que sempre encontram os mesmos alvos, e assim se repetiu a mesma lógica de aniquilamento na vida da menina de 8 anos. Ágatha Vitória Sales Félix foi morta com um tiro disparado nas costas no dia 20 de outubro de 2019. Segundo o tio da Ágatha, eles estavam em uma Kombi, voltando para a casa, e o veículo parou para que alguns moradores pudessem descer com suas sacolas de compras. A menina foi atingida neste exato momento. Segundo as testemunhas, não havia confronto. "Foi só um único tiro. A moto passou, os policiais desconfiaram da moto, atiraram em cima da moto e acertaram na Kombi onde estava a minha sobrinha", afirmou Danilo Félix, tio da menina.

Jenifer Silene Gomes sonhava ser ginasta. Katia Cilene, sua mãe, estava empenhada em ajudar a filha a realiza-lo e prometeu matriculá-la em uma aula de ginástica. Contudo, os projetos e percursos foram bruscamente interrompidos. Jenifer fazia o que mais gostava - brincar com as amigas - quando foi brutalmente arrancada do seu bem mais precioso: no dia 14 de fevereiro de 2019, a menina de 11 anos perdeu a vida. Ela estava brincando em frente ao bar de sua família quando foi baleada no peito: "Minha filha estava na porta do meu bar conversando com quatro crianças. De repente saíram quatro disparos e ela virou pra mim: 'Mãe, tô baleada'. 0 tiro pegou no peito da minha filha, como é que pode?", disse Kátia em frente ao Hospital Salgado Filho, no Méier, onde Jenifer foi socorrida (Ferreira, 2019). 
Kauê Ribeiro dos Santos foi uma criança que conheceu desde cedo a dureza de viver em uma sociedade desigual e violenta. Teve que trabalhar vendendo doces nos cruzamentos para sobreviver e ajudar com as despesas de casa. Era uma criança alegre, sonhadora e cheia de esperança, conforme descreveram os amigos e parentes próximos. Por onde passava, o menino deixava seu sorriso. Em um país majoritariamente apaixonado por futebol, não é de se estranhar que ele sonhasse ser um grande jogador. Kauê que queria conhecer Neymar e ser um atleta famoso como ele. Após mais um domingo de trabalho, talvez cansado e com fome, Kauê voltava para casa. Moradores relatam que meninos subiram a rua e policiais desceram atirando. Kauê foi morto com um tiro de fuzil na cabeça. Elivelton Feliciano Gomes, professor do Kauê na escolinha de futebol, declarou:

Eu tinha ele como meu filho, todo mundo sabe. Não porque era o melhor, mas porque era um menino sem palavras, com um coração do tamanho do mundo, o que ele tivesse que fazer para ajudar, ele iria fazer. Sua vida foi tirada assim, brutalmente... (Nascimento, 2019)

Os meninos do Complexo do Chapadão e de outras comunidades estão destinados a ser alvos da brutalidade sob a justificativa ilegítima de serem traficantes. 0 depoimento de Nádia Santos, tia de Kauê, ilustra bem essa realidade:

Um policial dizer que o Kauê era envolvido é porque ele quer esconder o despreparo dele. Porque ele está despreparado e que ele volte para a academia de policial, para poder ser um policial. Porque eles têm que proteger, não matar. (...) Atirar na cabeça de uma criança?! (...) Por quê? Por que ele é preto? Por que ele é negro? Por que ele é pobre? (Meteoro Brasil, 2019)

Kauan Noslinde Pimenta Peixoto foi um menino que, como muitas outras crianças, aprendeu a conviver com a separação dos pais. Kauan levava uma vida tranquila com a sua mãe. A cada quinze dias o menino visitava o seu pai em Mesquita, na Baixada Fluminense. Morar na Favela da Chatuba apresenta algumas condições que restringem e constrangem o exercício do direito de ir e vir. Há uma regra não escrita, mas consensual entre os moradores: esvaziem as ruas quando os policiais estiverem no território. Uma regra aparentemente contraditória, afinal, se aqueles que deveriam proteger a população estão atuando no território, a população local deveria ter mais segurança para exercer seus direitos básicos, como o de ir a uma lanchonete. Em um sábado à noite, dia 16 de março de 2019, Kauan, de 12 anos, foi convidado a seguir a lei não escrita da comunidade. Um parente de Kauan relatou o seguinte:

Eles saíram para comprar lanche em uma lanchonete lá perto. Assim que chegaram na Rua Rondon Gonçalves com a Rua Magno de Carvalho, os poli- 
ciais estavam vindo pela Rondon de encontro a eles. 0 pessoal que estava na rua evacuou. 0 menino falou: “Corre, Kauan! Corre, Kauan!'. Ele falou: 'Correr nada. Não fiz nada. Correr pra quê?', e ficou parado (Meteoro Brasil, 2019).

O menino tinha total razão: quando não se comete nenhum crime, não há porque ter medo dos agentes da justiça e dos promotores da segurança. Porém, quando se é morador da periferia, pobre e preto, os dispositivos de promoção de segurança e justiça se apresentam subversivos.

A Blazer parou e um policial já desceu atirando em direção a ele. Um tiro pegou no abdômen. Ele caiu encostado no muro. 0 policial se aproximou, e ele falou que era morador. Deram um tiro na perna dele e depois algemaram ele. Pegaram pela bermuda e jogaram ele na Blazer. Os outros policiais ficaram catando as cápsulas todinhas. Não deixaram uma cápsula pra trás. Não tinha tiroteio, a mãe do menino completou (Parentes de menino..., 2019, sección “Introdução”)

Marcelo de Guimarães, um homem negro de 38 anos, foi morto na manhã do dia 4 de janeiro de 2021, uma segunda-feira, após deixar seu filho de 5 anos numa escola de futebol. Ele era morador da Cidade de Deus, uma comunidade na Zona Oeste do Rio de Janeiro, e ninguém sabe o motivo pelo qual a Polícia Militar fez o disparo de fuzil. João Alberto Silva Freitas, de 40 anos, homem negro, foi morto em um supermercado de Porto Alegre, maior cidade da região Sul do Brasil, no dia 20 de novembro de 2020. A esposa relata que João Alberto discutiu com a fiscal do supermercado, e os responsáveis pela execução - um policial militar e o segurança do estabelecimento - o espancaram até a morte. Era o dia da Consciência Negra - dia da execução de Zumbi dos Palmares, o último líder do maior quilombo do período colonial.

\section{ASCESE NEGRA}

A partir de agora considero tudo blues

O samba é blues, o rock é blues, o jazz é blues

O funk é blues, o soul é blues

Eu sou Exu do Blues

Tudo que quando era preto era do demônio

E depois virou branco e foi aceito eu vou chamar de Blues

É isso, entenda

Jesus é blues

(Baco Exu do Blues, 2018)

Em 1943, o pintor moderno uruguaio Joaquín Torres-García operou um movimento de inversão na posição global da América do Sul. A América invertida, desenho feito à caneta e tinta, representa o continente virado em relação à 
sua representação padrão. Realiza, assim, uma torção nas estruturas perceptivas do espaço e das supostas hierarquias geopolíticas e pátrias. O Norte desaparece em sua obra e, por um jogo de linhas - longitudes, posição solar de referência, rosa dos ventos -, o hemisfério de referência global torna-se o sul. Em um texto publicado antes da obra, chamado $A$ Escola do Sul, diz ele:

Chamei isso de "A Escola do Sul" porque, na realidade, nosso Norte é o Sul. Não deve haver norte para nós, exceto em oposição ao nosso sul. Portanto, agora viramos o mapa de cabeça para baixo, e então temos uma ideia verdadeira de nossa posição, e não como o resto do mundo deseja. A ponta da América, de agora em diante, para sempre, aponta insistentemente para o Sul, nosso Norte (Torres-García apud Maria, 2011).

Qual seria a intenção do artista ao promover a afirmação pictórica de que a América é o nosso sul - e de que é a ela que devemos nos dirigir? A partir de que subterfúgios estéticos se opera a mutabilidade das posições e, no limite, do próprio conceito do que seria sul e norte? Que experiência sensível podemos fazer com nós mesmos ao tomarmos noção de uma América produtora do sul ou, em outros termos, de uma escola do sul?

Evidentemente, a aposta não se dá em direção a um identitarismo sulista como uma espécie de desejo pela pureza, pela essência ou pela hierarquia de poder político, econômico e cultural. Entretanto, não se pode esquecer que, sob a lógica do terceiro excluído, ser sul é ser não-norte, assim como ser norte é ser não-sul - e é preciso forjar uma ética a partir dessa diferenciação que não seja o pleno espelho daquilo que todas as dominações europeias e brancas já operaram subjetivamente no mundo. A aposta no negativo requer necessariamente a possibilidade de todas e todos sermos capazes de dinamizar forças diferenciais em relação ao norte, que, é preciso admitir, em alguma medida todas e todos nós somos. Trata-se, assim, de insistir em apontar para a transversão dos polos gravitacionais: escolher, sempre, os nossos nortes a partir da potência de outridade do Sul na "verdadeira ideia de nossa posição", como escreveu Torres-García no texto que acompanha a pintura aqui mencionada.

Na década de 1980, o filósofo e professor do Collège de France, Michel Foucault, retorna repentinamente aos estudos da Grécia Antiga que havia abandonado no começo dos anos 1970. Em seus quatro últimos cursos na prestigiosa instituição de ensino parisiense, entre 1981 e 1984, profere aulas sobre o estudo das relações de cuidado de si e delimita três momentos desta prática: socrático-platônico, helenístico-romano e cristão. 
Célebre por pensar os jogos de poder em instituições como a prisão, o manicômio, a escola e o quartel, Foucault, naquele momento, montava a tese de que o período helenístico-romano, antes da instituição do cristianismo, foi marcado por uma intensidade enorme da relação de cuidado de si como prática de subjetivação. Na aula do dia 17 de março de 1982, no curso intitulado A hermenêutica do sujeito, Foucault lembra do especialista em Grécia Antiga, E. R. Dodds:

A hipótese de Dodds, retomada por Vernant e por Joly, considera que, ao entrar em contato com as civilizações do nordeste europeu (graças às navegações no Mar Negro), no século VII, os gregos encontraram-se em presença de certas práticas xamânicas e de técnicas de si próprias daquela forma de cultura. (...). Logo, deve-se ou não admitir uma continuidade? Deve-se, com efeito, considerar ter havido algo como uma transferência, uma implantação e ao mesmo tempo uma decantação dessas práticas essencialmente mágicas e somáticas, tornadas práticas filosóficas e espirituais? São de dois conjuntos diferentes de práticas que não se pode aproximar? (Foucault, 2006, p. 135)

Como uma apropriação consciente do negativo, para usar o termo forjado por Chela Sandoval e citado por Donna Haraway em seu Manifesto Ciborgue (2013), assumimos tal palavra, tal catalogação e tal categorização racial e racista em sua força de inversão daquilo que os naturalistas intentavam ao forjá-la: como uma aposta de potência, ancestralidade, autonomia e resistência ao processo que, desde a biopolítica da plantation (Mbembe, 2018), marcou todo o território global. Assim, através da escolha de fazer do Sul o nosso Norte - e aqui evidentemente trata-se de políticas de subjetivação -, é preciso buscar efetivar o que há de deriva menor, tal como Deleuze e Guattari (1996) demonstram em Mil Platôs: ou seja, é no jogo micropolítico que o devir-negro-no-mundo deve ser transformado em ponto de resistência, deixando de ser um modo de aprisionamento e tornando-se um modo de liberdade em uma relação de si para consigo. Assim, a dimensão estética e política da resistência nos impele a fazer de nossas vidas polos gravitacionais e ativações do que é descontínuo - de saberes e práticas locais e desqualificadas. Deste modo, a busca deixaria de ter como meta uma essência qualquer e se enviesaria em uma travessia que o professor brasileiro Muniz Sodré definiu em seu livro Pensar nagô (2017) como uma "ética da plenitude corporal do sujeito" (p. 108), em que o corpóreo é o encontro ativo entre palavra e vida e entre postura e prática.

Sabe-se que tal diretriz pode ser encontrada nas religiões de matriz africana que, mesmo sob todas as tentativas históricas de silenciamento, a preço de sangue, segue a prática de culto aos orixás. No livro supracitado, Sodré introduz o pensamento da arkhé como uma possibilidade de percepção dos proces- 
sos subjetivos que o terreiro monta como uma relação ética com o mundo, a comunidade e o sensível. A arkhé, como uma realidade manifestada, é:

Sentida como irradiação de uma corporeidade ativa, da qual provém a potência (axé) com seus modos de comunhão e diferenciação. E o sensível enquanto protodisposição originária do comum que engendra a unidade dos sentidos e a conversão analógica (não dialética) de uns nos outros, desvelando a conaturalidade ou copertencimento entre corpo e mundo. (Sodré, 2017, p. 83)

A diretriz de uma corporeidade ativa do sujeito - muito próxima ao que Foucault chamava de uma relação de si ao estudar a Grécia Antiga em seus derradeiros cursos - só é efetiva se ela for traçada no contato com outrem: a "arkhé como a própria continuidade do grupo" (Sodré, 2017, p. 96). Mas como fazer do grupo uma relação do comum e não um movimento gregário exclusivo e excludente? Qual o risco necessariamente endossado ao direcionarmos a aposta pela menoridade na vontade de continuação de um grupo?

Talvez seja possível afirmar uma ética preta comungada à experiência sensível: a ancestralidade perpassada não apenas pela via dos cultos, mitos e rituais, mas também - e talvez principalmente - pela perpetuação de viver ininterruptamente sob o risco de morte e, ainda assim, e em alguns casos justamente por isso, seguir fazendo da própria vida uma obra de arte. Mbembe (2018) chama de devir-negro do mundo a "condição fungível e solúvel, fazendo da institucionalização um padrão de vida" (p. 20) em que a condição negra da plantation pode se alastrar a todo e qualquer corpo. O devir, como movimento contínuo de um estatuto necessariamente contingente, serve como bússola de uma negritude mundial integrada que sabe de cor e décor - de pele e de coração as regras do jogo em que a qualquer momento pode ser aniquilada, vendida, amordaçada e invadida. Também por isso, é necessário contar, rememorar e testemunhar as tecnologias criadas todos os anos, em que mesmo mergulhados em um jogo mortífero, combinamos não nos esvairmos e continuar no processo de ruptura e de insistência na vida de uma ancestralidade ética, de outra relação de si e para com o outro, na aposta de sermos simultaneamente diferentes e semelhantes: uma ascese negra (Mbembe, 2018) como enfrentamento à necropolítica tropical - mas para isso é preciso que estejamos vivos.

\section{PROTESTOS MOLECULARES}

No Complexo do Alemão, no dia 22 de outubro de 2019, um sentimento de tensão e revolta se espalhou e impregnou os moradores da região. Durante o enterro da menina Ágatha Felix, de 8 anos, "amigos e familiares gritaram por Justiça e aplaudiram no momento em que Ágatha foi enterrada" (Entenda co- 
mo..., 2019, sección "Morte e despedida”). Ficava evidente que a palavra de ordem era "queremos paz e justiça!". Faixas e balões amarelos cobriram toda a avenida em direção ao cemitério de Inhaúma, bairro da zona norte no município do Rio de Janeiro.

O protesto evidenciava a condição de guerra que se perpetua há anos, uma guerra que parece não ter fim. Todavia, esse fluxo que se espalhava e contagiava todo o país mostrou que a resistência não deixaria de existir:

0 que nós pedimos é que se use o cérebro nas ações policiais, para que os cidadãos de bem seja a prioridade, de modo que não vejamos mais inocentes derramando os seus sangues em um cenário de segurança pública que reedita tudo que foi feito nos anos anteriores e não trouxe a solução para o problema da violência (depoimento de Antônio Carlos Costa, Presidente da ONG Rio de Paz). (Entenda como..., 2019)

Revolta, desejo de revolução: “Nós exigimos justiça!”. Por mais que toda a dor afligisse os corações dos familiares e de todos que sentiram empatia pela fatalidade da morte de Ágatha, não houve espaço para o silêncio. O que se ouviu foi o brado que exigia o direito à vida.

Era fevereiro de 2019, as ruas do bairro de Triagem, outro bairro da zona norte do Rio de Janeiro, pegavam fogo, assim como os corações dos moradores. Naquele mesmo dia, Jenifer Silene Gomes havia sido morta com um tiro no peito. Os moradores pareciam já conhecer aquela história e, completamente exaustos de vivenciarem novamente a mesma situação, foram incendiar ônibus e ruas, e a motivação parecia ser clara: "Moradores da região acusam policiais militares de serem os autores dos disparos. A Polícia Militar, no entanto, afirma que a criança já estava morta quando equipes chegaram ao local e a socorreram" (Peixoto, 2019). A versão por parte dos policiais era flagrantemente mentirosa e causou a revolta da população. Não apenas a versão falsa, mas também toda a estrutura que faz com que se repita a mesma lógica de aniquilamento. Por consequência, o desejo de botar fogo na estrutura de destruição de vida se expressou nas ruas e ônibus do bairro. Mais uma vez os moradores se negaram a tratar aquela realidade como normal, só houve espaço para a revolta.

"Eles combinaram de nos matar, mas nós combinamos de não morrer" - assim Conceição Evaristo (2014, p. 7) deixou explícito o combinado com todos os corpos que diariamente reivindicam o direito à vida. As vozes negras gritam em protesto em todos os lugares em que o racismo se apresenta como letal e iminente. A molecularidade da resistência se expande e cada vez alcança novos espaços. Historicamente se tentou, pelo processo de escravização, colonização, apartheid e com a invenção da raça, silenciar vida negras. A luta vem na direção justamente oposta: o movimento negro tem como um dos seus vetores a 
união, o chamamento para a rua, a fim de evidenciar a sua experiência, exigir respeito e legitimar o direito à vida. A artista e militante Bia Ferreira disserta com precisão em sua canção "Cota não é esmola" sobre esses acontecimentos, e convida quem a ouve a um agenciamento a esse fluxo de resistência:

São nações escravizadas

E culturas assassinadas

É a voz que ecoa do tambor

Chega junto, venha cá

Você também pode lutar, ei!

E aprender a respeitar

Porque o povo preto veio para revolucionar

(...) Não deixe calar a nossa voz, não!

Não deixe calar a nossa voz, não!

Revolução.

(Showlivre, 2018)

A música é um chamado e uma denúncia. É assim que operam os protestos moleculares: convoca, se espalha, dá notoriedade, faz fluir fluxos que visam a um outro mundo possível. Frente à máquina de fazer morrer pretos e pobres, não desejamos apagar a realidade, e é exatamente no limiar entre a necropolítica e a busca pelo viver que o movimento que nos interessa aqui reafirma a que veio. O cantor Sant disserta:

Pra cada momento da vida, existirá um verso do Racionais

Pra cada morto ou detento, resistirão cem novos de nós

Pra que sempre leiam tais versos como uma alforria pra nossos iguais

Pra que esses olhos se encham de brilho, somos sós!

(Rap Box, 2018)

Quando políticas neofascistas buscam a todo momento escamotear a realidade a fim de construir uma narrativa que abre campo para práticas genocidas, protestos moleculares encontram na própria possibilidade ferramentas para resistir: protestos $\mathrm{fati}^{2}$. Bia Ferreira (Showlivre, 2018) expressa: "Nascem milhares dos nossos cada vez que um nosso cai. E é peito aberto, espadachim do gueto, nigga samurai!", colocando em evidência o conhecimento do sangue que é derramado pelo maquinário estrutural mortífero.

Presentemente eu posso me considerar um sujeito de sorte Porque apesar de muito moço me sinto são e salvo e forte E tenho comigo pensado, Deus é brasileiro e anda do meu lado E assim já não posso sofrer no ano passado

\footnotetext{
${ }^{2}$ Neologismo a partir da noção de amor fati do filósofo Friedrich Nietzsche.
} 
Tenho sangrado demais, tenho chorado pra cachorro

Ano passado eu morri mas esse ano eu não morro.

(Belchior, Sujeito de Sorte, 2018)

Em 1984, Michel Foucault concedeu uma entrevista a dois estudantes universitários estadunidenses. Foi uma das últimas entrevistas concedidas pelo filósofo. Ao explicitar seu processo de pesquisa, indaga: "não poderia a vida de todos se transformar numa obra de arte? Por que deveria uma lâmpada ou uma casa ser um objeto de arte, e não a nossa vida?" (Foucault, 1995, p. 261). A vida como obra de arte se torna, então, a matriz ética, política e estética da coragem de fazer da vida um processo de fazer-se - uma autopoiese da vida. Pela via de fazer diferentemente do que já foi traçado para sentir, agir e pensar outras estruturas.

A aposta insinuada por Foucault torna-se um desafio para a psicologia desde que ela seja entendida como uma disciplina que, mais do que pelas profundezas da interioridade humana, se interessa pelos processos de subjetivação. Em que medida cabe à nossa área a análise das experiências subjetivas vividas por brasileiros e brasileiras que, necessariamente, estão atravessados pela alegria e tristeza de ser desta terra? Concretamente, é possível pensar a psicologia dissociada aos problemas da necropolítica instituída na democracia, na cidade e no modo de vida da qual somos efeitos? Se nossa direção ético-política se faz na insistência da vida - éthos de passagem de mundo - de pretos e pretas brasileiros, então a empreitada, de cunho clínico-político deve necessariamente se interrogar como operar essa experiência no tracejado da experiência comum do Brasil.

Será possível formarmos um ponto de ver apto a perceber as forças de nossas marcas minoritárias? Em Transversais da Subjetividade (Mizoguchi e Passos, 2021), a demanda para a psicologia é assumida quando "a potência de produção da diferença foi sucumbida pelo produto supostamente final” (p. 59). Ou seja, a psicologia deve ir ao encontro deste limite entre a diferença e a repetição dos processos subjetivos. Nesse sentido, o que estamos modulando nesta discussão sobre o racismo é a força subjetiva que a psicologia interroga e problematiza no entrelaçamento entre a clínica e a política. A tarefa da psicologia seria, portanto, compor forças que nos ajudem a ser outros - e, aqui, um outro país, mais apto a enfrentar suas chagas jamais enfrentadas.

$\mathrm{Na}$ qualidade de menor estamos sempre à deriva, encontrando - e inventando - novas estratégias de vida, de alegria, de festa, de culto, de transcendência e fazendo de nossas vidas uma insistência vivida em comum. Achille Mbembe (2018), em Crítica da razão negra, diz que a condição de escravidão operou um modo de experiência na qual o sujeito teve que se tornar "empreendedor de si 
mesmo e se transformar num sujeito capaz de se projetar no futuro e de se dedicar a um desejo" (p. 267). Ou seja, o sujeito escravizado teve que se autoproduzir "não como repetição, mas como diferença irresolúvel e singularidade absoluta" (p. 267). E é nesse circuito no qual se entende a vida como obra de arte e as condições de vida como possibilidades de invenção de outros paradigmas é que abarcamos a possibilidade de apostar, mais uma vez, na insistência de viver - pela certeza que temos de que a vida é nossa e que podemos fazer dela obra, insistência e arte, e que essa é uma tarefa à qual a Psicologia não pode se furtar.

\section{REFERÊNCIAS}

Adorno, Luís (24 de agosto de 2017). Abordagem nos Jardins tem de ser diferente da periferia, diz o novo comandante da Rota. Notícias UOL. https://noticias.uol.com.br/cotidiano/ultimas-noticias/2017/08/24/abordagem-nojardins-e-na-periferia-tem-de-ser-diferente-diz-novo-comandante-da-rota.htm

Baco Exu do Blues (2018, 23 de novembro). Bluesman [Vídeo]. YouTube. https: / / www.youtube. com/watch?app=desktop\&v=82pH37Y0qC8

Deleuze, Gilles \& Guattari, Félix (1996). Mil platôs: capitalismo e esquizofrenia (vol. 4). Editora 34.

Entenda como foi a morte da menina Ágatha no Complexo do Alemão, segundo a família e a PM. (2019, 23 de setembro). G1 Rio. https://g1.globo.com/rj/rio-dejaneiro/noticia/2019/09/23/entenda-como-foi-a-morte-da-menina-agatha-nocomplexo-do-alemao-zona-norte-do-rio.ghtml

Evaristo, Conceição (2017). Becos de memória. Editora Pallas.

Ferreira, Lucas (2019, 15 de fevereiro). Criança de 11 anos morta com tiro de fuzil sonhava em ser ginasta. Notícias R7. https:// noticias.r7.com/rio-de-janeiro/criancade-11-anos-morta-com-tiro-de-fuzil-sonhava-em-ser-ginasta-15022019

Foucault, Michel (1979). Microfísica do poder. Edições Graal.

Foucault, Michel (1995) Sobre a genealogia da ética. Uma revisão do trabalho. In: Paul Rabinow \& Hubert Dreyfus (Eds.), Michel Foucault. Uma trajetória filosófica. Para além do estruturalismo e da hermenêutica (pp. 253-278). Forense Universitária.

Foucault, Michel (2006). A hermenêutica do sujeito: curso dado no Collège de France (1981-1982). Martins Fontes.

Gimenes, Lúcio Flávio de Santana \& Mizoguchi, Danichi H. (2019). Neoliberalismo e segurança: investigações a partir da obra de Michel Foucault. Revista de Ciências Humanas, 53, 1-9. https://doi.org/10.5007/2178-4582.2019.e74163

Haraway, Donna (2013). Manifesto ciborgue: ciência, tecnologia e feminismosocialista no final do século XX. Autêntica Editora.

Lei $\mathrm{n}^{\circ} 13.675$, de 11 de junho de 2018. Disciplina a organização e o funcionamento dos órgãos responsáveis pela segurança pública e dá outras providências. Câmara dos Deputados. Centro de Documentação e Informação. 
https: / / www2.camara.leg.br/legin/fed/lei/2018/lei-13675-11-junho-2018-786843publicacaooriginal-155823-pl.html

Maria (2011, 30 de novembro). Inverted Map of South America. Urban Media Archaeology. https: / /www.wordsinspace.net/urban-media-archaeology/2011fall/2011/11/30/inverted-map-of-south-america/

Mbembe, Achille (2018). Crítica da razão negra. n-1 edições.

Meteoro Brasil (18 de dezembro de 2019). As crianças que a PMRJ matou [Vídeo]. YouTube.

https://www.youtube.com/watch?app=desktop\&v=PaO3ncpVvPc\&feature=youtu.be

Mizoguchi, Danichi H. \& Passos, Eduardo (2021). Transversais da subjetividade: arte, clínica e política. EdUFRJ.

Nabuco, Joaquim (1976). Minha formação. Livraria José Olympio Editora.

Nascimento, Tatiana (2019, 9 de setembro). Menino de 12 anos morto durante operação da PM no Chapadão é enterrado. G1 Rio. https://g1.globo.com/rj/rio-dejaneiro/noticia/2019/09/09/menino-de-12-anos-morto-durante-operacao-da-pm-nochapadao-e-enterrado.ghtml

Parentes de menino morto na Chatuba, RJ acusam a polícia: 'Ficaram catando as cápsulas todinhas' (2019, 18 de março). TV Globo e G1 Rio. https://g1.globo.com/rj/riode-janeiro/noticia/2019/03/18/parentes-de-menino-morto-na-chatuba-rj-acusam-apolicia-ficaram-catando-as-capsulas-

todinhas.ghtml?fbclid=IwAR1K22wHvVYeHEj6PPCFoTVpiPUORFAsu_kf_vVzXxiAMHo3WISo8 ateZWE

Peixoto, Ari (2019, 14 de fevereiro). Criança morre baleada na Zona Norte e moradores acusam policiais de serem os autores de disparo. G1 Rio. https://g1.globo.com/rj/rio-de-janeiro/noticia/2019/02/14/crianca-morre-baleadana-zona-norte-e-moradores-bloqueiam-o-transito-em-protesto.ghtml

Projeto de Lei $n^{\circ} 556$, de 10 de junho de 1999. Altera o Artigo 32 da Lei $n^{\circ}$ 443/81 que dispõe sobre o estatuto dos Policiais Militares do Estado do Rio de Janeiro e dá outras providências. Assembleia Legislativa do Estado do Rio de Janeiro (Alerj). http://alerjln1.alerj.rj.gov.br/scpro99.nsf/4d633dd91fb4d668832567040007dd93/06 db4ee3d083943203256790006365fc?OpenDocument\&ExpandView

Rap Box (2018, 6 de junho). Orgânico \#4 - Seja forte [Vídeo]. YouTube. https://www.youtube.com/watch?app=desktop\&v=BcKcj14SKx8\&feature=youtu.be

Showlivre (24 de julho de 2018). Bia Ferreira - Cota Não é Esmola [Vídeo]. YouTube. https: / / www.youtube.com/watch?app=desktop\&v=0d5roQ3ZWAw\&feature=youtu.be

Sodré, Muniz (2017). Pensar nagô. Vozes.

Sujeito de sorte $(2018,21$ de julho). Belchior - tema [Vídeo] YouTube. https://www.youtube.com/watch?app=desktop\&v=5MV_Fa3MQuA

Veloso, Caetano (2012, 15 de agosto). Caetano Veloso - Haiti [Vídeo]. YouTube. https: / / www.youtube.com/watch?app=desktop\&v=MfAxBoxdlb0\&feature=youtu.be 


\section{WALDENILSON TEIXEIRA RAMOS}

Graduando da Universidade Federal Fluminense no curso de psicologia e professor voluntário de redação do Grupo Diversidade de Niterói. Tem experiência na área de Psicologia, com ênfase em Psicologia Social, atuando principalmente nos seguintes temas: subjetividade e clínica.

waldenilsonramos@id.uff.br

https: //orcid.org/0000-0002-3485-0455

\section{DEBORA INÊZ BRANDÃO}

Graduanda em Psicologia na Universidade Federal Fluminense. Bolsista de Iniciação Científica do grupo de pesquisa "Da subjetividade à coragem: modulações da verdade dos últimos cursos de Michel Foucault".

deborainez@id.uff.br

https://orcid.org/0000-0002-8232-7511

\section{MAURO ANDRADE SILVA}

Psicólogo, com mestrado em psicologia na linha: subjetividade, política e exclusão social. Pesquisa a escrita de si e a negritude. Atuou por quase dez anos no SUS, mais diretamente na reforma psiquiátrica. Atualmente trabalha com Acompanhamento Terapêutico e Atendimento Clínico.

mauroansilva@gmail.com

https://orcid.org/0000-0003-1399-5505

\section{DANICHI HAUSEN MIZOGUCHI}

Professor do Departamento e do Programa de Pós-Graduação em Psicologia da Universidade Federal Fluminense.

danichihm@hotmail.com

http://orcid.org/0000-0002-7147-3521

\section{FORMATO DE CITACIÓN}

Ramos, Waldenilson Teixeira; Brandão, Debora Inêz; Andrade Silva, Mauro \& Hausen Mizoguchi, Danichi (2021). As relações entre o Estado e a população pobre e negra no Brasil: necropolítica tropical. Quaderns de Psicologia, 23(3), e1784.

https: / / doi.org/10.5565/rev/qpsicologia.1784

\section{HISTORIA EDITORIAL}

Recibido: 31-01-2021

$1^{\text {a }}$ revisión: 12-04-2021

Aceptado: 26-04-2021

Publicado: 25-01-2022 